\title{
Stabilized hypochlorous acid, a topical therapeutic strategy for Trichomonas vaginalis infection: An in vitro study
}

\author{
Original İbrahim Yildiz ${ }^{1}$, Evren Tileklioğlü ${ }^{1}$, Özgenur Yilmaz ${ }^{2}$, Hatice Ertabaklar ${ }^{1}$, \\ Article Sarhan Sakarya ${ }^{3}$
}

Departments of Parasitology ${ }^{1}$, Microbiology $^{2}$, and Infectious Diseases ${ }^{3}$, Aydin Adnan Menderes University School of Medicine, Aydin, Turkey and Institute of Health Science, Aydin, Turkey ${ }^{2}$

\begin{abstract}
Background: Trichomonas vaginalis (TV) parasitic protozoan is a widespread sexually transmitted infection. It is emphasized by the World Health Organization that the global prevalence of TV is rising. The parasite causes infections in the urogenital system in humans, and recently it was determined that it has a potential effect on both prostate and cervical cancer. Due to its being a significant public health problem, new treatment methods need to be developed to combat the parasite.

Objectives: Previous studies on the use of stabilized hypochlorous acid ( $\mathrm{HOCl})$ indicated that it has a potential microbicidal effect on different types of microorganisms. From this point, we investigated the effect of stabilized $\mathrm{HOCl}$ on TV in vitro.

Material and Methods: Direct microscopy for time-kill (TK) assay, and vital trypan blue assay were performed to determinate the effective dose (1/2 to $1 / 64$ dilution) and time ( 0 to $90 \mathrm{~min}$ ) of stabilized $\mathrm{HOCl}$ action on live TV. For negative controls, sterile PBS alone was added to TV and medium.

Results: The death of TV was dose and time dependent. Parasites were killed at a dilution of $1 / 2$ and $1 / 4$ at 0 min and for the rest of the time courses at these dilutions. Whereas, decreased effect was observed on TV viability with dilutions of $1 / 8,1 / 16$ and $1 / 32$ with different time courses and there was no effect at a dilution of $1 / 64$.

Conclusion: According to our findings, stabilized HOCl has an effect on TV viability and this is the first study on the effect of $\mathrm{HOCl}$ on TV.
\end{abstract}

Keywords: Stabilized hypochlorous acid, Trichomonas vaginalis, therapeutic agents.

Received: 13 March, 2020, Accepted: 19 April, 2020.

Corresponding Author: Evren Tileklioğlu, Tel. No.: +90 05055875400, Email: etileklioglu@gmail.com.

Print ISSN: 1687-7942, Online ISSN: 2090-2646, Vol. 13, No. 1, April, 2020.

\section{INTRODUCTION}

Trichomonas vaginalis (TV) is a flagellated parasitic protozoan. It does not have a cyst form, but it has been reported that under certain circumstances it can be transformed to pseudocyst form ${ }^{[1]}$. It is a widespread sexually transmitted parasite. It may cause a persistent infection in adult females involving the vagina, urethra and endocervix; and may cause prostatitis, epididymitis and decrease the motility of sperm cells in men $^{[2,3]}$. Recent studies showed that it may have a potential effect on both prostate and cervical cancer ${ }^{[4,5]}$. The World Health Organization reported the high incidence rate of 276 million new cases each year ${ }^{[6]}$. Nitroimidazole, metronidazole or tinidazole are treatment agents for TV and the increasing recurrence of infections due to resistance and side effects of these antibiotics encouraged scientists to find an alternative treatment $t^{[7,8]}$. Recent studies propose the investigation of the effects of additional synthetic and natural products other than antibiotics against $\mathrm{TV}^{[9,10]}$.
Stabilized HOCl is a weak acid, naturally produced by the myeloperoxidase activation of neutrophils while undergoing phagocytosis ${ }^{[11,12]}$. It reacts with various functional groups of proteins, carbohydrates, lipids and their bio-conjugates by oxidation, resulting in a powerful microbicidal effect that overcomes pathogens ${ }^{[13,14]}$. In vitro synthesized stabilized HOCl has been known to demonstrate a powerful antimicrobial effect in wounds against numerous bacterial, viral, fungal pathogens and prions ${ }^{[15,16]}$. Stabilized $\mathrm{HOCl}$ is naturally produced by the innate immune system. It eradicates microorganisms, reduces inflammation via inhibition of mast cell degranulation and inflammatory cytokines, reduces itching and pain, increases oxygenation of wound sites to improve healing, and breaks down biofilms ${ }^{[17]}$. While it is effective against numerous microorganisms, there are limited studies evaluating its effect on parasites ${ }^{[18-21]}$. Herein we aimed to investigate the effect of stabilized $\mathrm{HOCl}$ on TV in vitro, as an intro to its use as topical application in the form of vaginal douche or cream. 


\section{MATERIAL AND METHODS}

This analytical descriptive study was conducted in Aydin Adnan Menderes University Faculty of Medicine Department of Parasitology, Turkey, between 2019 and 2020.

Reagents: Commercially available stabilized $\mathrm{HOCl}$ which is generated by reverse reaction of sodium hypochlorite and hydrogen peroxide was used. The composition of the solution used in this study was 218 ppm, pH 7.1, ORP $871 \mathrm{MV}$, stable for 24 months (NPS Biocidal, Istanbul, Turkey).

T. vaginalis culture: Cryopreserved TV isolate was thawed and grown in a trypticase-yeast-extractmaltose (TYM) medium prepared as described by Ertabaklar et al. ${ }^{[22]}$. Before assay, $6 \mathrm{ml}$ of TYM medium was incubated at $37^{\circ} \mathrm{C}$ for three days. The number of parasites was counted in a hemocytometer counting chamber and adjusted to an average number of $8 \times 10^{5}$ flagellates $/ \mathrm{ml}$. The culture was centrifuged at $600 \mathrm{rpm}$ for $5 \mathrm{~min}$, and the supernatant was discarded.

Time kill (TK) assay: To resuspend the flagellates, $3 \mathrm{ml}$ of sterile phosphate buffered saline (PBS) was added to the pellet. $\mathrm{HOCl}$ solution with serial dilutions of $1 / 2,1 / 4,1 / 8,1 / 16,1 / 32$, and $1 / 64(109,55,22.5$, $11,5.5$, and $2.75 \mathrm{ppm}$, respectively) were prepared in sterile PBS. Briefly, $100 \mu \mathrm{l}$ of stabilized HOCl dilutions were added into a 96-well microtiter plate, followed by the addition of $25 \mu$ of flagellates-PBS mixture and $75 \mu \mathrm{l}$ of TYM medium to reach a final number of $2 \mathrm{x}$ $10^{5}$ flagellates/well. For negative controls, sterile PBS alone with TV and medium were used. The plate was incubated for $0,10,30,60,90 \mathrm{~min}$ at $37^{\circ} \mathrm{C}$ to investigate the TK effect of stabilized $\mathrm{HOCl}$ solution on the flagellates. Evaluation of the results was by: (1) Direct microscopy of each dilution; (2) Vital trypan blue assay to identify and count the dead forms of the flagellates (Fig.1 A and B); (3) Re-culture to verify the effective concentrations on the viability of the flagellates.

Statistical analysis: All experiments were conducted three times and control condition was assayed in triplicate. Analysis of variance (ANOVA) was used to compare the mean responses among experimental and control experiments. A $P$ value below 0.05 was considered statistically significant.

\section{RESULTS}

According to the TK assay, we determined the lethal effect of stabilized $\mathrm{HOCl}$ dilutions at various times by direct microscopy, vital trypan blue, and reculture exclusion to determine the number of viable parasites (Figure 1A). Positivity was confirmed in TYM culture without stabilized HOCl (Fig. 1B). The lethal rate was $100 \%$ with trypan blue exclusion at all time intervals with $1 / 2$ dilution, and at $90 \mathrm{~min}$ with $1 / 4$ dilution. The lethal rate with $1 / 4$ dilution was $82.3 \%$, $94.33 \%, 98.66 \%$ and $99.33 \%$ at $0,10,30$ and $60 \mathrm{~min}$ respectively. The effect of stabilized $\mathrm{HOCl}$ gradually decreased at a dilution of $1 / 8,1 / 16$ and $1 / 32$ and the lethal effect increased with the pre-defined time intervals at these dilutions. There was no effect at a dilution of 1/64 (Table 1). These data indicated that stabilized $\mathrm{HOCl}$ has dose and time dependent effect on TV (Figures 2 and 3, respectively).

Table 1. Minimal parasitical concentrations and time kill of stabilized HOCl to T. vaginalis.






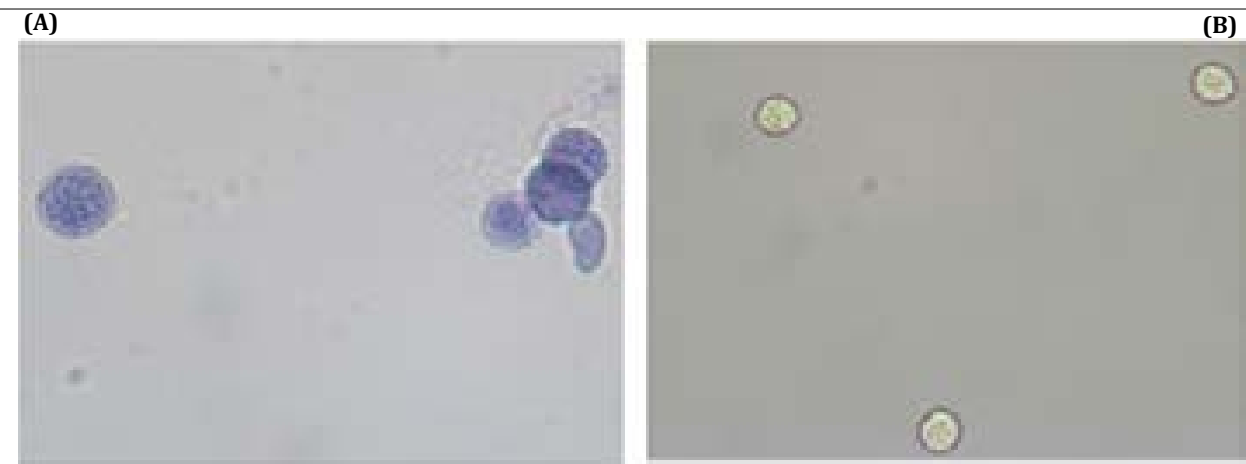

Fig. 1. (A) Effect of $1 / 2$ dilution of stabilized HOCL on T. vaginalis at 0 min; dead forms of parasites stained with vital trypan blue. (B) Control live parasites in the absence of $\mathrm{HOCl}$.

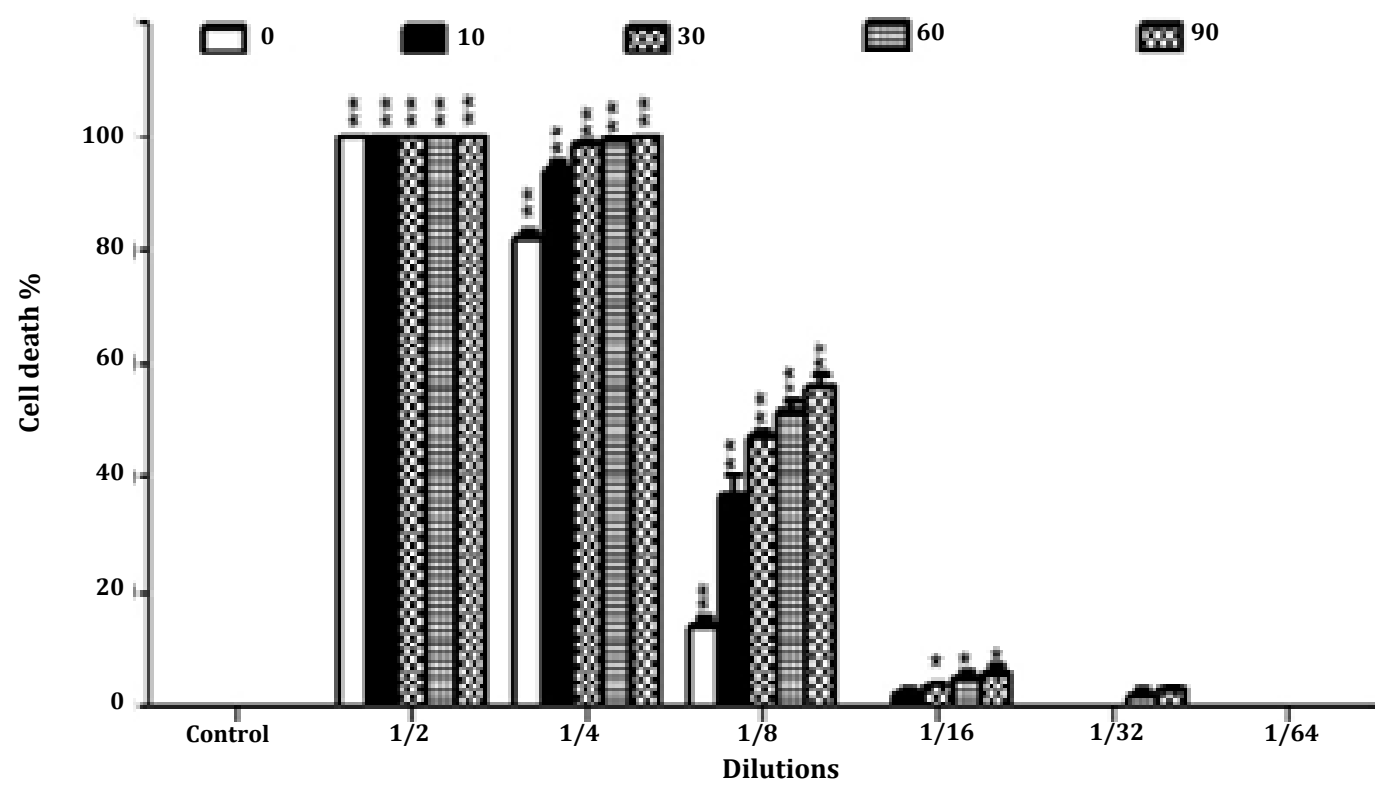

Fig 2. Effect of different dose responses to stabilized HOCl on T. vaginalis.

* $P<0.001$, and ${ }^{* *} P<0.0001$ significant decrease in viability of T. vaginalis in stabilized $\mathrm{HOCl}$ solution compared to the media control.

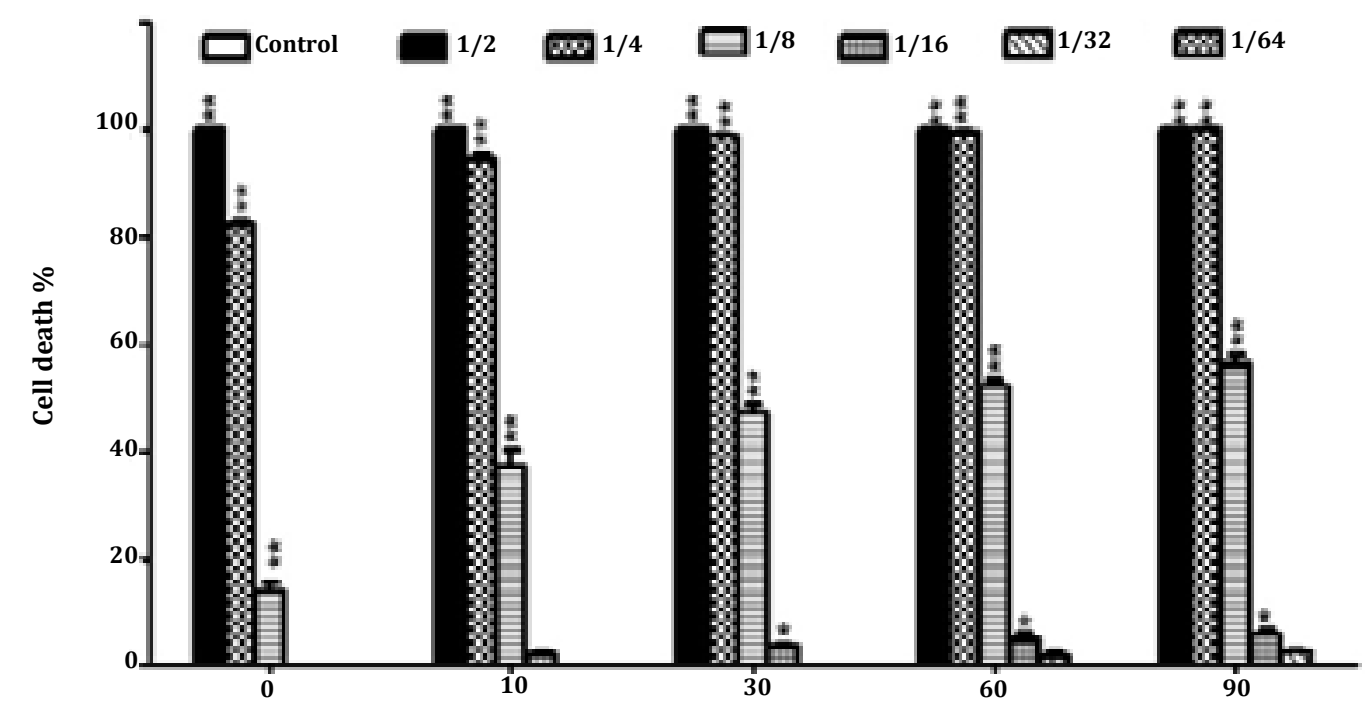

Fig 3. Effect of different time responses of stabilized $\mathrm{HOCl}$ on T. vaginalis.

${ }^{*} P<0.001$, and ${ }^{* *} P<0.0001$ significant decrease in viability of $T$. vaginalis in stabilized $\mathrm{HOCl}$ solution compared to the media control. 


\section{DISCUSSION}

Trichomonas vaginalis infection is the most common sexually transmitted disease worldwide. The disease is a basically curable sexually transmitted infection. In neglected female cases it may cause severe health consequences such as cervical cancer, infertility, HIV acquisition and adverse pregnancy outcomes leading to premature rupture of placental membranes in advances cases $^{[23]}$. Trichomoniasis is generally asymptomatic in men, but recent studies indicate that TV has a potential effect on prostate cancer ${ }^{[24]}$.

The reported standard regimen for treatment of trichomoniasis is based on nitroimidazole-derived therapy, mainly metronidazole ${ }^{[25]}$. The recommended oral dose for both men and women (pregnant/ non-pregnant) is $2 \mathrm{~g}$ single dose, or a 7 day-dose therapy (400 or $500 \mathrm{mg}$ twice daily for 7 days) ${ }^{[26]}$. A metanalysis of published comparisons reported that multidose metronidazole is superior to single-dose metronidazole for the treatment of trichomoniasis in a randomized controlled trial done in women with HIV infection ${ }^{[27]}$. Also, trichomoniasis can be cured by the use of tinidazole $\mathrm{e}^{[28]}$. Oral or parenteral tinidazole and metronidazole have been approved for treatment in TV infections with cure rates of $92-100 \%$ and $85-$ $95 \%$ respectively ${ }^{[29,30]}$. Additionally, topical treatment, particularly vaginal douching in women is used for personal hygiene or aesthetic reasons, for preventing or treating an infection ${ }^{[31]}$. A recent meta-analysis showed that no adverse outcomes or evidence of teratogenicity or mutagenic effects have been recorded for metronidazole used during pregnancy. But, it is still not clear whether metronidazole will have any adverse effect on pregnancy outcomes ${ }^{[32]}$. Other in vitro studies indicated that $2.4-9.6 \%$ of isolates showed resistance to metronidazole ${ }^{[33]}$.

The high prevalence of TV, antibiotic resistance and limited tolerability, and toxicity to nitroimidazoles suggest that alternative treatment regimens are needed ${ }^{[34,35]}$. An updated review provided comprehensive information on certain natural and synthetic compounds, and their modes of action ${ }^{[36]}$. In recent studies, a wide variety of herbal compounds were tested for anti-trichomonal activity in vitro ${ }^{[37-40]}$. Also inactivated Lactobacillus acidophilus, boric acid and other parasitic agents (benzimidazoles) were tested in vitro or in vivo against anti-trichomonal infections $^{[41-43]}$. In spite of the reported attempts for treatment with various compounds, an epidemiological study from South Korea reported that incidence of TV has increased ${ }^{[44]}$

Besides of its use in recorded TV infections, vaginal douching using an antiseptic has been applied against pathogens associated with pelvic inflammatory disease, vaginitis, cervical cancer, low birth weight, preterm birth, sexually transmitted diseases, ectopic pregnancy, and infertility ${ }^{[45-47]}$. It is reported that douching with various products leads to deterioration of the vagina flora especially lactobacilli that prevent other potential pathogens from colonization or overgrowth ${ }^{[48]}$. Topical vaginal medications and pessaries such as povidone iodine clotrimazole, paromomycin, furazolidone, used by women reduced the symptoms of trichomoniasis, while a two month course of intravaginal boric acid completely eradicated the infection ${ }^{[49]}$.

Cellular immunity plays a key role against harmful pathogens and creates chemicals such as reactive oxygen species. It activates neutrophils that produce hydrogen peroxide $\left(\mathrm{H}_{2} \mathrm{O}_{2}\right)$, and the activated granule enzyme myeloperoxidase converts $\mathrm{H}_{2} \mathrm{O}_{2}$ into $\mathrm{HOCl}$ in the presence of $\mathrm{Cl}^{-}$and $\mathrm{H}^{+[50]}$. Commercial production of stabilized $\mathrm{HOCl}$ has become possible through electrolysis of sodium chloride brine. Accordingly it may be used against microorganisms causing loss of their intracellular contents, inhibition of protein synthesis and depressed DNA synthesis ${ }^{[1,52]}$. Therefore, we aimed to test stabilized $\mathrm{HOCl}$ which is naturally produced in human, generated by the immune response as a bactericidal oxidant. Its eco-friendly property and ability to degrade the infectivity of prions and its active biocidal agent for wound care, encouraged us to study its effect on TV in vitro ${ }^{[53-55]}$.

In the literature, there is no in vitro study performed against TV using stabilized HOCl. Thus, ours is the first study to report that stabilized $\mathrm{HOCl}$ has time and dose dependent effect on $\mathrm{TV}$, being effective at a dilution of $1 / 2$ and $1 / 4$ within $0-10$ minutes. Whereas a dose and time dependent decrease was observed at dilutions of $1 / 8,1 / 16$ and 1/32; and no effect was observed at a dilution of $1 / 64$.

Conclusion: This in vitro study supports the topical use of stabilized $\mathrm{HOCl}$ solution for its powerful and parasiticidal effect on TV trophozoites. Stabilized HOCl is widely used as an antiseptic in many fields due to its lethal effect on microorganisms. Foremost, this study has determined that stabilized $\mathrm{HOCl}$ can also be a highly effective agent in trichomoniasis. However, further studies need to be implemented to evaluate its in vivo application.

Conflicts of interest: Authors state that they have no conflicts of interest.

Funding statement: No financial support for the research, authorship, and/or publication of this article.

\section{REFERENCES}

1. Sutcliffe S, Neace C, Magnuson NS, Reeves R, Alderete JF. Trichomonosis, a common curable STI, and prostate carcinogenesis: a proposed molecular mechanism. PLoS Pathog 2012; 8(8): e1002801. 
2. Hezarjaribi HZ, Fakhar M, Shokri A, Teshnizi SH, Sadough A, Taghavi M. Trichomonas vaginalis infection among Iranian general population of women: a systematic review and meta-analysis. Parasitol Res 2015; 114(4):1291-1300.

3. Seo MY, Im SJ, Gu NY, Kim JH, Chung YH, Ahn MH, et al. Inflammatory response of prostate epithelial cells to stimulation by Trichomonas vaginalis. Prostate 2014;74(4):441-449.

4. Fowke JH, Han X, Alderete JF, Moses KA, Signorello LB, Blot WJ. A prospective study of Trichomonas vaginalis and prostate cancer risk among African American men. BMC Res Notes 2016; 18(9):224.

5. Silva LC, Miranda AE, Batalha RS, Monte RL, Talhari S. Trichomonas vaginalis and associated factors among women living with HIV/AIDS in Amazonas, Brazil. Braz J Infect Dis 2013; 17(6):701-703.

6. Rowley J, Vander Hoorn S, Korenromp E, Low N, Unemo M, Abu-Raddad L, et al. Chlamydia, gonorrhoea, trichomoniasis and syphilis: global prevalence and incidence estimates, 2016. Bull World Health Organ, 2019; 97(8): 548.

7. Conrad MD, Bradic M, Warring SD, Gorman AW, Carlton JM. Getting trichy: tools and approaches to interrogating Trichomonas vaginalis in a post-genome world. Trends Parasitol 2013; 29(1):17-25.

8. Schwebke JR, Barrientes FJ. Prevalence of Trichomonas vaginalis isolates with resistance to metronidazole and tinidazole. Antimicrob Agents Chemother 2006; 50(12):4209-4210.

9. Gokmen AA, Can H, Kayalar H, Pektaş B, Kaya S. In vitro anti-Trichomonas vaginalis activity of Haplophyllum myrtifolium. J Infect Dev Ctries 2019, 13(03): 240-244.

10. Da Silva CC, Pacheco BS, das Neves RN, Alves MSD,SenaLopes Â, Moura S, et al. Anti-parasitic activity of synthetic curcumin monocarbonyl analogues against Trichomonas vaginalis. Biomed Pharmacother 2019; 111: 367-377.

11. Fu X, Kassim SY, Parks WC, Heinecke JW. Hypochlorous acid generated by myeloperoxidase modifies adjacent tryptophan and glycine residues in the catalytic domain of matrix metalloproteinase-7 (matrilysin): an oxidative mechanism for restraining proteolytic activity during inflammation. Int J Biol Chem 2003; 278(31): 2840328409.

12. Vissers MC, Winterbourn CC. Oxidation of intracellular glutathione after exposure of human red blood cells to hypochlorous acid. Biochem J 1995;307 (1):57-62.

13. Grisham MB, Jefferson MM, Melton DF, Thomas EL. Chlorination of endogenous amines by isolated neutrophils. Ammonia-dependent bactericidal, cytotoxic, and cytolytic activities of the chloramines. Int J Biol Chem 1984; 259(16):10404-104013.

14. McKenna SM, Davies KJ. The inhibition of bacterial growth by hypochlorous acid. Possible role in the bactericidal activity of phagocytes. Biochem J 1988;254(3):685-692.

15. Hughson AG, Race B, Kraus A, Sangare LR, Robins L, Groveman BR, et al. Inactivation of prions and amyloid seeds with hypochlorous acid. PLoS Pathog 2016;12(9): e1005914.
16. Ishihara M, Murakami K, Fukuda K, Nakamura $S$, Kuwabara M, Hattori H, et al. Stability of weakly acidic hypochlorous acid solution with microbicidal activity. Biocontrol Sci 2017; 22(4), 223-227.

17. Kiamco MM, Zmuda HM, Mohamed A, Call DR, Raval YS, Patel R, et al. Hypochlorous-acid-generating electrochemical scaffold for treatment of wound biofilms. Scientific Reports 2019; 9(1): 1-13.

18. Xie X, Wang J, Yan Y, Zhang X, Liu C, Yang J, et al. A new mitochondria-targeted ratiometric fluorescent probe based on diketopyrrolopyrrole for imaging endogenous HOCl in living cells. Analyst 2018; 143(23): 5736-5743.

19. Prokopowicz ZM, Arce F, Biedron R, Chiang CLL, Ciszek M, Katz DR, et al. Hypochlorous acid: a natural adjuvant that facilitates antigen processing, cross-priming, and the induction of adaptive immunity. J Immunol 2010; 184(2), 824-835.

20. Yildiz I, Yilmaz O, Tileklioglu E, Sakarya S, Ertabaklar H. Stabilised hypochlorous acid: A new therapeutic strategy against parasitic eye infection agent Acanthamoeba spp. J Environ Prot Ecol 2018;19(3):1397-1404.

21. Park SC, Shin SP, Kim MS, Cho SH, Kim JH, Jr CHC, et al. Antimicrobial effect of hypochlorous acid on pathogenic microorganisms. J Prev Vet Med 2013; 37(1): 49-52.

22. Ertabaklar H, Caner A, Doskaya M, Demirtas LO, Toz SO, Ertug S, et al. Comparison of polymerase chain reaction with wet mount and culture methods for the diagnosis of trichomoniasis. Turkiye Parazitol Derg 2011;35(1):1-5.

23. Ilekis JV, Tsilou E, Fisher S, Abrahams VM, Soares MJ, Cross JC, et al. Placental origins of adverse pregnancy outcomes: potential molecular targets: an executive workshop summary of the Eunice Kennedy Shriver National Institute of Child Health and Human Development. Am J Obstet Gynecol 2016; 215(1): 1-46.

24. Mielczarek E, Joanna B. Trichomonas vaginalis: pathogenicity and potential role in human reproductive failure. Infection 2016; 4(44): 447-458.

25. de Brum VP, Tasca T, Evan Secor W. Challenges and persistent questions in the treatment of trichomoniasis. Curr Top Med Chem 2017; 17(11): 1249-1265.

26. Workowski KA, Bolan GA. Sexually transmitted diseases treatment guidelines, 2015.MMWR Recommendations and reports: Morbidity and mortality weekly report recommendations and reports. CDC 2015; 64(RR-03):1137.

27. Howe K, Kissinger PJ. Single dose compared with multidose metronidazole for the treatment of trichomoniasis in women: a meta-analysis. Sex Transm Dis 2017; 44: 30-35.

28. Sobel JD, Nyirjesy P, Brown W. Tinidazole therapy for metronidazole-resistant vaginal trichomoniasis. Clin Infect Dis 2001; 33(8): 1341-1346.

29. Apte VV, Packard RS. Tinidazole in the treatment of trichomoniasis, giardiasis and amoebiasis. Report of a multicentre study. Drugs 1978;15: 43-8.

30. Thin RN, Symonds MA, Booker R, Cook S, Langlet F. Double-blind comparison of a single dose and a five-day course of metronidazole in the treatment of trichomoniasis. Br J Vener Dis 1979;55(5):354-356. 
31. Martino JL, Vermund SH. Vaginal douching: evidence for risks or benefits to women's health. Epidemiol Rev 2002; 24(2):109-124.

32. Gulmezoglu AM, Azhar M. Interventions for trichomoniasis in pregnancy. Cochrane Database Syst Rev 2011; 11(5):CD000220.

33. Schmid G, Narcisi E, Mosure D, Secor WE, Higgins J, Moreno H. Prevalence of metronidazole-resistant Trichomonas vaginalis in a gynecology clinic. J Reprod Med 2001; 46(6): 545-549.

34. Johnston VJ, Mabey DC. Global epidemiology and control of Trichomonas vaginalis. Curr Opin Infect Dis 2008; 21(1):56-64.

35. Ertebaklar H, Karadam-Yaman S, Malatyalı E, Ertuğ S. Investigation of in vitro metronidazole resistance in the clinical isolates of Trichomonas vaginalis. Mikrobiyol Bul 2016, 50(4): 552-558.

36. Vieira PB, Giordani RB, Macedo AJ, Tasca T. Natural and synthetic compound anti Trichomonas vaginalis: an update review. Parasitol Res 2015; 114:1249-1261.

37. Mohammed RG, Ali JF. Effects of Iraqi medicinal plants on the growth of Trichomonas vaginalis in vitro: A narrative review. Indian J Public Health Res Dev 2019; 10(8): 1039-1043.

38. Mahmoud MA, Aminou HA, Hashem HA. Are the fatty acids responsible for the higher effect of oil and alcoholic extract of Nigella sativa over its aqueous extract on Trichomonas vaginalis trophozoites? J Parasit Dis 2016; 40(1): 22-31.

39. Ertabaklar H, Kivçak B, Mert T, Töz SÖ. In vitro activity of Arbutus unedo leaf extracts against Trichomonas vaginalis trophozoites. Türkiye Parazitol Derg 2009; 33(4): 263-265.

40. Gökmen AA, Kayalar H, Pektaş B, Selçuk KAYA. Investigation of in vitro anti-trichomoniasis effect of Nigella sativa oil against Trichomonas vaginalis. İzmir Katip Çelebi Üniversitesi Sağllk Bilimleri Fakültesi Dergisi 2018; 3(3): 7-10.

41. Kinghorn GR, British Co-operative Clinical Group. An investigation, by questionnaire, of cases of recalcitrant vaginal trichomoniasis seen in genitourinary medicine clinics in the United Kingdom. Inter J STD \& AIDS 1992; 3(1): 24-27.

42. Backus KV; Muzny CA, Beauchamps LS. Trichomonas vaginalis treated with boric acid in a metronidazole allergic female. Sex Transm Dis, 2017, 44(2): 120.

43. KoroshT, BujansE, Morada M, Karaalioglu C, Vanden Eynde JJ, Mayence A, et al. Potential of bisbenzimidazole- analogs toward metronidazole-resistant Trichomonas vaginalis isolates. Chemical Biology \& Drug Design 2017; 90(4): 489-495.

44. Joo SY, Goo YK, Ryu JS, Lee SE, Lee WK, Chung DI, et al. Epidemiology of trichomoniasis in South Korea and increasing trend in incidence, health insurance review and assessment 2009-2014. PloS One 2016; 11(12).

45. Short MB, Black WR, Flynn K. Discussions of vaginal douching with family members. J Pediatr Adolesc Gynecol 2010; 23(1): 39-44.

46. Lichtenstein B, Nansel TR. Women's douching practices and related attitudes: findings from four focus groups. Women \& Health 2001; 31(2-3): 117-131.

47. Ege E, Timur S, Zincir H, Egri M, Sunar Reeder B. Women's douching practices and related attitudes in eastern Turkey. J Obst Gynaecol Res 2007; 33(3): 353-359.

48. Martino JL, Vermund SH. Vaginal douching: evidence for risks or benefits to women's health. Epidemiol Rev 2002; 24(2): 109-124.

49. Muzny C, Barnes A, Mena L. Symptomatic Trichomonas vaginalis infection in the setting of severe nitroimidazole allergy: successful treatment with boric acid. Sex Health 2012;9(4):389-391.

50. Vissers VC, Winterbourn CC. Oxidation of intracellular glutathione after exposure of human red blood cells to hypochlorous acid. Biochem J 1995; 307(1): 57-62.

51. Barrette WC, Albrich JM, Hurst JK. Hypochlorous acidpromoted loss of metabolic energy in Escherichia coli. Infect and Immun 1987; 55(10): 2518-2525.

52. Rutala WA, Weber DJ. Disinfection, sterilization, and antisepsis: Principles, practices, current issues, new research, and new technologies. Am J Infect Control 2019; 47: A1-A2.

53. Ramalingam S, Cai B, WongJ, Twomey M, Chen R, Fu RM, et al. Antiviral innate immune response in non-myeloid cells is augmented by chloride ions via an increase in intracellular hypochlorous acid levels. Sci Rep 2018; 8(1): 1-11.

54. Ono T, Yamashita K, Murayama T, Sato T. Microbicidal effect of weak acid hypochlorous solution on various microorganisms. Biocontrol Sci 2012; 17(3): 129-133.

55. Sakarya S, Gunay N, Karakulak M, Ozturk B, Ertugrul B. Hypochlorous acid: an ideal wound care agent with powerful microbicidal, antibiofilm, and wound healing potency. Wounds 2014; 26(12): 342-350. 